\title{
MAKING EFFECTIVENESS CUSTOMER COMPLAINT HANDLING
}

\author{
Rezi Muhamad Taufik Permana1, Roro Arinda Reswanti Julian Pratama ${ }^{2}$ \\ Universitas Islam Bandung ${ }^{*}$, Indonesia ${ }^{1}$, Universitas Langlangbuana, Bandung ${ }^{2}$ \\ rezi.muhamad@gmail.com ${ }^{\star 1}$, roro.arinda@gmail.com²
}

\begin{abstract}
The quality of service provided by each Bank becomes a differentiator and becomes a consideration for customers to be loyal to the Bank. With increasing competition in the service and manufacturing sectors, the strategic focus has shifted to determining retention strategies for customers. The speed of handling complaints is measured by SLA (Services Level Agreement), where each bank is required to settle customer complaints a maximum of 20 working days. For this reason, the company has a great responsibility to be able to handle customer complaints following the established SLA (Services Level Agreement). Risk of reputation and even financial risk can arise if customer complaints are not handled quickly and accurately. The research method uses PDCA (plan, do check, action) to know how the business process can be a continuous improvement. This research will show what the effect of complaint handling is too late with the root causes method. To give feedback from the problem this research uses decision-making tools as Analytic Hierarchy Process.
\end{abstract}

Keywords: Customer Complaint Handling, Services Level Agreement, Decision Making, Analytic Hierarchy Process

\section{INTRODUCTION}

Banks play an important role by contributing as an intermediary function, facilitating economic activities, and representing most state financial institutions (Marshal \& Ahmed, 2015). The business efficiency of the process in each activity in the banking industry becomes more important to be carried out consistently. Changes or shifts in the financial industry are an important thing to do in the era of industry transformation today. On the other side, service in the financial industry, in this case, the banking sector is required to make a breakthrough so that the service expectations provided to customers are better and faster. Every bank vying to win the competition and become a differentiation with other banks with optimal service goals.

Now the competitive environment has encouraged the customers to become more demanding regarding their product purchases, in complaining about poor after-sales service, product quality, and value for the money spent (Brownlie \& Lemond, 1992). The services provided by the
Bank are not only focused on physical services (Customer Services), but the services of handling customer complaints (Complaint Handling) that are fast, accurate, and solution are very important for customers when experiencing difficulties or obstacles when making transactions. The company must identify the factors that cause consumers to complain and cause their success (Taleghani et al, 2011). Consumers are true without response if there is dissatisfaction with the services provided and it tends that dissatisfied consumers cannot take action after a poor purchasing experience. Doing nothing or not buying back a company's product or service is a legitimate response to dissatisfaction (Mowen \& Minor, 2008). Singh (2000) classifies consumers involved in behaviors such as "passive" (Stauss, \& Seidel 2004).

Complaints are defined as statements that something is wrong or not good enough (Braga, 2007); an expression dissatisfaction about service standards; action or lack of action by an organization to someone (Gbettor, et.al, 2014). Complaint handling is useful to resolve and learn 
from the failure of the service to reestablish the reliability of the organization in front of customers (Hart et al, 1990). Data from a customer are the key to quality management because it can be used to correct problems with service design. data can be useful information for companies that are managed by a qualified "complaint management system". Where there is a complaints management system that is a gradual way to receive, record, process, respond to complaints and use them to improve service and decision making. Handling complaints effectively requires the systematic logging of complaints data that will enable a sound analysis of the causes of problems.

The speed of handling complaints is measured by SLA (Services Level Agreement), where each bank is required to settle customer complaints about a maximum of 20 working days in the Indonesia Regulation. For this reason, the company has a great responsibility to be able to handle customer complaints in accordance with the established SLA (Services Level Agreement). A sense of customer satisfaction is conceptualized as a thorough loyalty study of consumer experience with service providers, not just specific transactions based on satisfaction ratings (Moliner et.al, 2006). Risk of reputation and even financial risk can arise if customer complaints are not handled quickly and accurately. Consumer complaints are useful for information sources that help organizations identify several sources of dissatisfaction (Nyer, 2000). As a company that has a high reputation that has the trust of the wider community throughout Indonesia, the company has a strong commitment to every customer complaint that can be resolved in accordance with the established SLA (Services Level Agreement). Organizations should not wait for customers to report complaints, instead of asking customers regularly about their satisfaction with service levels is said to be the key to maintaining loyalty (Tehubijuluw, 2016).

At the end of 2018, the latest version of the customer complaint handling system has been implemented. Where the application aims to cut the process business so that it can produce a faster and more accurate resolution of customer complaints. Over time until the end of Maret 2019, the number of customer complaints that have not been resolved for more than 20 working days has reached 7.452 Trouble Ticket. Where this has the potential for a hard complaint that results in the company's reputation decreasing. For comparison, until the end of 2018 , the number of Trouble Tickets that have not been completed for more than 20 Working Days is only 238 Trouble Tickets. 


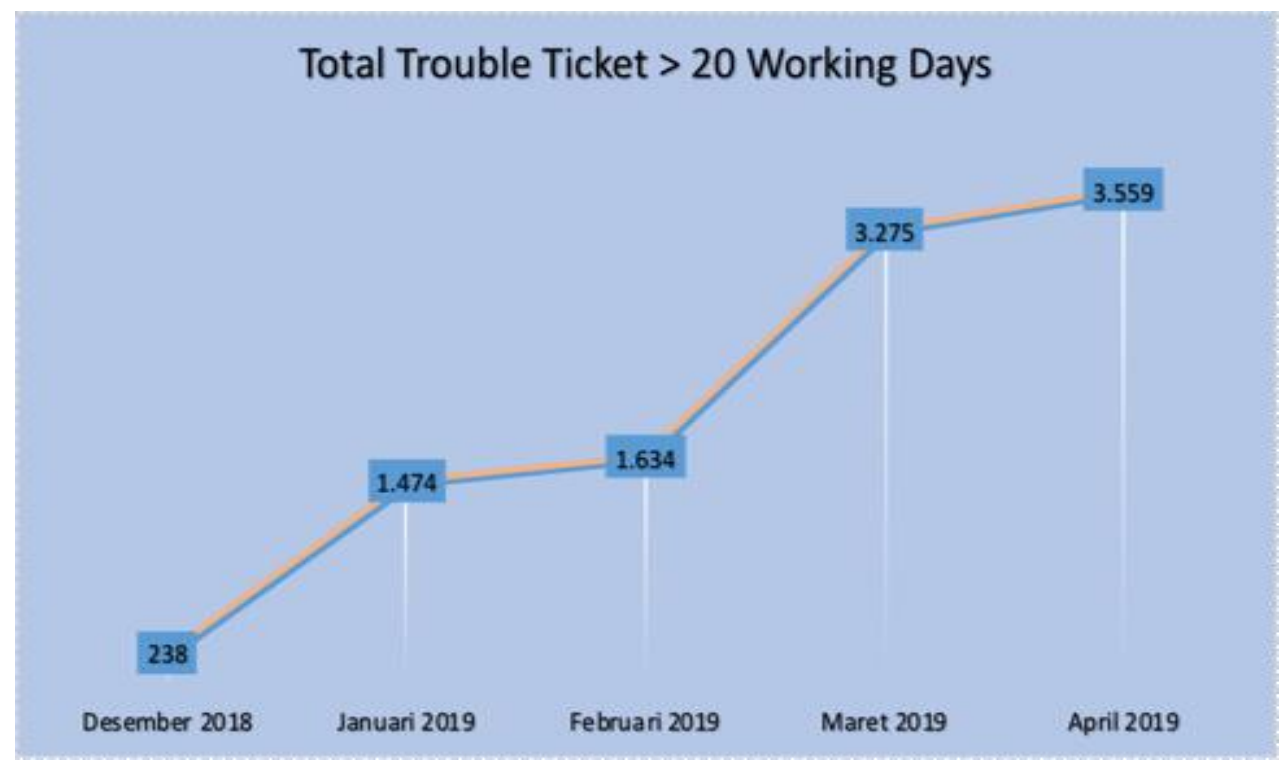

Figure 1. Total Complaint about SLA (20 Working Days)

Sources: Internal Document (2019)

In figure 1. shows the number of complaints that exceed services level agreement (SLA). A significant increase in the number of complaints that exceeded the completion SLA limit became the focus of the team to solve the problems that occurred. The application of the resolution of the complaint that has been implemented has become a focus in the internal discussion forum of the company because there are complaints about the reliability and format which is quite complicated compared to the previous customer complaint application.

The main objective of this research to analyse effective handling complaints. There are three main objectives of the research are follows: identify the current condition of handling the complaint; Determine factor-factor make a complaint handling problem; Provide a reference to which effective complaint handling

\section{METHODS}

The conceptual framework is a limitation that will be used to find business solutions to the problems faced in customer complaint handling. Currently, complaint handling is an issue that is vital for the banking industry, where the key security-related trust company in accordance with quickly and appropriately. The overall business process in the handling of complaints can not be separated from the application documenting complaints. Related to the transition, application of accountability, there are several problems caused by all stakeholders in the handling. The main problem is that the speed of discussion is hampered by complaints that are not resolved for more than 20 working days (over SLA). For that in analysing the causes of these problems, the author will analyze the causes of the problem of internal factors.

The approach used by the authors in this study through the interview method and for the quantitative method uses secondary data sourced from the company's internal data. This study uses literature review sourced from books, journals, and other research similar to the approach of problems that occur in this study, as well as to find the best solution.

In the deepening stage, the root causes analysis study uses Fish Bone Diagrams which help in finding the main problems. The author uses PDCA Analysis to find business issues, root 
causes of the problem, and alternative solutions that at the end of this study will use the AHP Method Analysis to determine the best solution based on certain considerations.

The deepening stage the root causes analysis study uses Fish Bone Diagrams which help in finding the main problems. The author uses PDCA Analysis to find business issues, root causes of the problem, and alternative solutions that at the end of this study will use the AHP Method Analysis to determine the best solution based on certain considerations.

Root Causes Analysis is the most effective way to identify the most fundamental factors underlying the problem given (often deviation from an accepted performance). A root cause analysis is a "reactive" analysis that is carried out after the problem has occurred. Root cause analysis is part of a more general problem-solving process and an integral part of continuous improvement. To helps and identify the root causes, in this case, researchers use A fishbone diagram. A fishbone diagram is a possibility of causing various categories that branch off from the original problem. fishbone diagrams make it possible to have many subbranches branching from each of the categories identified.

\section{Deming wheel (PDCA) Analysis}

PDCA (Plan, do, check, action) is a management concept to meet customer quality requirements, which were originally developed by Dr. William Edward Deming. The PDCA cycle is useful for encouraging managers and employees to continuously plan improvements, implement them, examine the effectiveness and other processes, and in the process of implementing them (Lai \& Cheng 2009).

Usually, this cycle is repeated to ensure that the results are reliable. Quality tools can be implemented to support results and list potential causes of problems (Barsalou, 2016).

\section{Research Questions}

Interviews are the right method when there is a need to gather in-depth information about people's opinions, thoughts, experiences, and feelings. Interviews are useful when the topic of an investigation is related to a problem that requires complex questions and sufficient investigation. Interviews can be designed differently depending on the needs handled and the information. This research uses Semi-structured interviews where he interviewer uses a set of predetermined questions and respondent's answers in their own words. Some interviewers use topic guides that serve as checklists to provide information on the same topic, such as: (1) Do you think the customer complaint application is currently easy to use? (2) How fast do you think recorded complaints on the application compared to the previous application? (3) In your opinion, is the customer satisfied with the service in the complaints process? (4) How important do you think this application is in helping the customer complaint process? (5) What is the impact on your unit/branch when this application has a problem?

\section{RESULTS AND DISCUSSION Plan}

In determining the main objectives of this study, the authors use the SMART method. Which can be seen in the following table below: 
Table 1. SMART Methods

\begin{tabular}{ccl}
\hline Key Component & & \multicolumn{1}{c}{ Objective } \\
\hline Specific & - & Who: Division X in Banking Company, Vendor Application \\
& - What: failure to achieve an SLA of Complaint Handling. & Where: Division X \\
& - When: 2019 \\
& Which: An Involvement of IT and technology divisions in \\
the process of creating new applications for complaint \\
handling. \\
- Why: Handling the complaint process can be completed in \\
accordance with SLA.
\end{tabular}

Do

In this case, there are four main discussion such as system, policy, employee, and process. The fish-bone factors which from interview and diagram below will illustrate it:

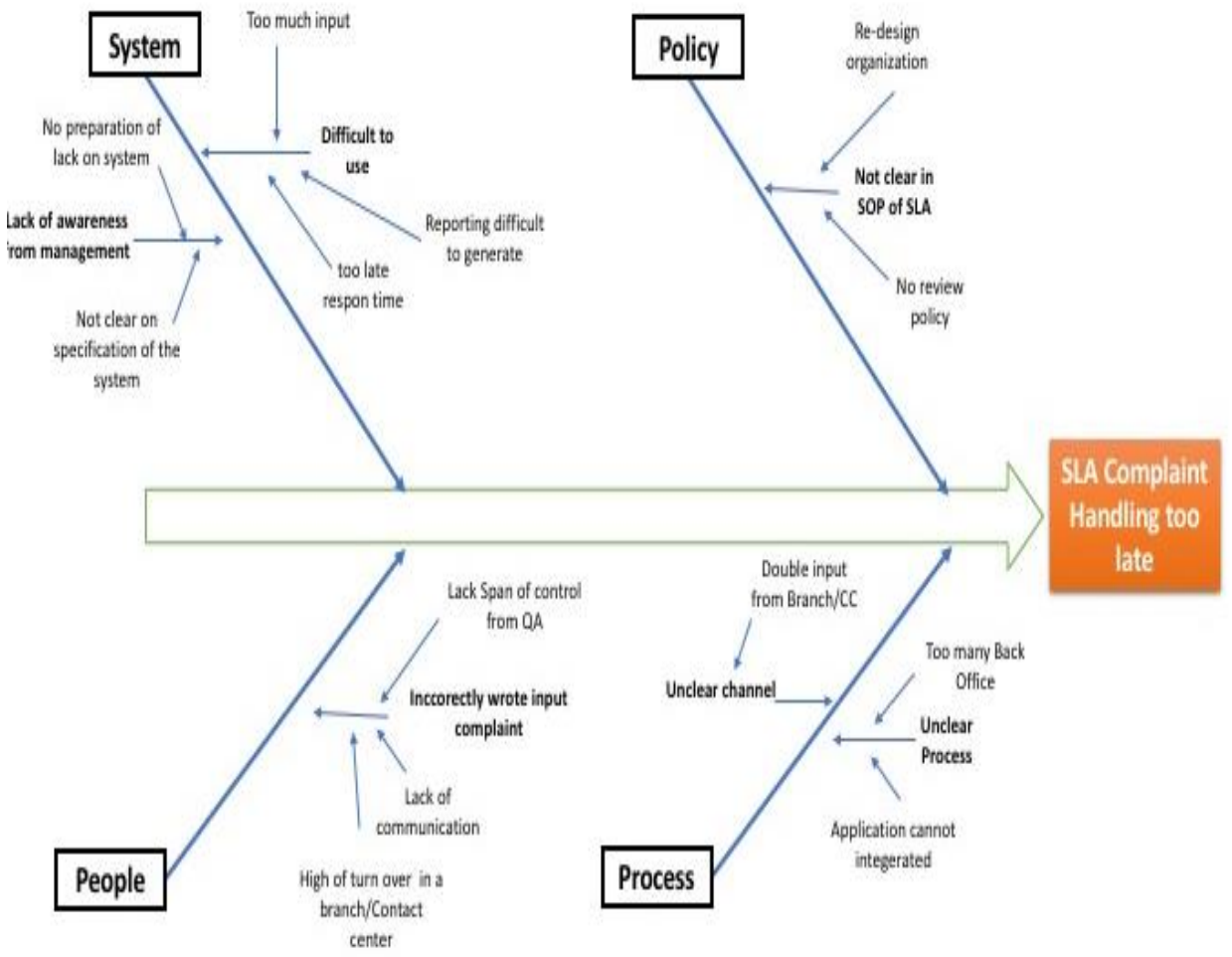

Figure 2. Fish Bone Diagram

Source: processed data (2020)

From the fishbone diagram, there is six possibility root cause that effect in late to be response and the solution of the complaint handling: 
Table 2. Root Causes

\begin{tabular}{llcc}
\hline \multirow{2}{*}{ Causes } & \multicolumn{1}{c}{ Sub-causes } & \multicolumn{2}{c}{ Effect } \\
& & Yes & No \\
\hline System & Difficult to uses & $\sqrt{ }$ & - \\
System & $\begin{array}{l}\text { Ladk of awareness } \\
\text { from management }\end{array}$ & - & $\sqrt{ }$ \\
People & $\begin{array}{l}\text { Incorrectly wrote input } \\
\text { complaint }\end{array}$ & - & $\sqrt{ }$ \\
Policy & $\begin{array}{l}\text { Not dear in SOP of } \\
\text { SLA }\end{array}$ & - & $\sqrt{ }$ \\
Process & Undear channel & - & $\sqrt{ }$ \\
Process & Undear process & - & $\sqrt{ }$ \\
\hline
\end{tabular}

Source: processed data (2020)

The main cause of the lengthy process of settlement of the complaint that caused the system/applications are difficult to use by Customer Services or Agent Contact Center to record complaint as well as the integration of applications that are not in line with expectations.

\section{Check}

Based on root causes analysis, it was found that the application was the main cause in on complaint handling process. The Fish Bone Diagram and interview conducted with the Management of the Service \& Contact Center Division, there were several alternative solutions to this problem. The several alternatives obtained are as follows:

\section{Alternative 1}

Create the New Complaint Handling Application, creating new applications is indeed not easy to do.

2. Alternative 2

Re-design complaint handling system, as it is known that the main cause of the problem is the late SLA Complaint Handling caused by the difficulty of the user in using the application.

3. Alternative 3

Using previous Complaint Handling Application, before the implementation new application the company has existing applications.
Set up the decision hierarchy:

The first level in the structure is the goal of this research, which is to develop a decision-making model of improvement for solving the SLA Complaint Handling problem. The four criteria are Reliability which has two sub-criteria, easy to use, speed of application. Then the second criterion, resources have two sub-criteria, Internal and vendor/external. Cost criteria have two sub-criteria, Operational cost and terminate a contract of a vendor. And the last criteria is time has three subcriteria, SOP Timing, time of input ticket. Then all alternatives will be assessed based on criteria and sub-criteria so that could get the best alternative from three alternatives existing.

\section{Best alternatives for business solution:}

After the three alternatives are assessed based on the criteria required using the AHP approach, then the results are shown by the below table.

Tabel 3. Result of alternatives

\begin{tabular}{lcc}
\hline Alternative & Score & Rank \\
\hline Alternative 1 & 0,289 & 2 \\
Alternative 2 & 0,571 & 1 \\
Alternative 3 & 0,135 & 3 \\
\hline \multicolumn{2}{c}{ Source: processed data (2020) }
\end{tabular}


So the best alternative for a business solution is alternative 2: $\mathrm{Re}$ design complaint handling system.

\section{CONCLUSION}

Proposed business solution for customer complaint handling on this study by assessing Internal Company are reduce the number of mandatory fields and choices of call types is limited to the system of complaint handling and reset the system by paying attention to the middleware infrastructure that is connected to the host.

The implementation plan for the re-design of the complaint handling application will begin with a meeting of all stakeholders involved which aims to plan the stages of the application development process. This is done as an effort from the decision making that has been done by considering other aspects that have been explained previously.

\section{REFERENCES}

Barsalou, M. (2016). The Quality Improvement Field Guide. Achieving and Maintaining Value in Your Organization. Boca Raton. Florida: CRC Press Taylor \& Francis Group.

Braga, Glaucia Karime. (2007). Complaint handling in pharmaceutical companies, Quality Assurance Journal, 11, 1621.

Brownlie, D.T., \& Lemond, K.A. (1992). Electrical retailing in the 1990s. International Journal of Retail \& Distribution Management, 20(3), 3-1.

Gbettor, EMA, Avorga SMK, Atatsi, EA. (2014). Handling customer complaints in the indigenous food vending industry, European Scientific Journal, 10(13), 681-96.

Hart, Christopher W. L., Heskett, James L., \& Jr, W. Earl Sasser (1990). The Profitable Art of Service Recovery. Harvard Business Review, 68. 148-56.

Lai K. \& Cheng T. (2009). Just-in-Time
Logistics. Surrey: Gower Publishing Limited.

Marshal Ahmad \& Ahmed, Emad. (2015). Effects of TQM Practices on Banking Sector Performance: The Case of Jordan. Journal of Applied Finance \& Banking, 5(6), 113-126 ISSN: 1792-6580 (print version), 1792-6599 (online) Scienpress Ltd.

Moliner, Sanchez, Rodruguez \& Callarisa. (2006). Quality Relationships with a Travel Agency: The Influence of the Postpurchase Perceived Value of a Tourism Package. The Journal of Tourism and Hospitality Research, 7,194-211.

Mowen, J. C \& Minor, M. (2008). Consumer Behavior, 5 th ed. Englewood Cliffs, New Jersey: Prentice-Hall,

Nyer, PU. (2000). An investigation into whether complaining can cause increased consumer satisfaction. Journal of Consumer Marketing, 17(1), 9-19.

Singh, J. (2000). A typology of consumer dissatisfaction response styles. Journal of Retailing, Vol. 66 (1), 57- 99.

Stauss, B \& Seidel, W. (2004). Complaint Management - The Heart of CRM. Mason, $\mathrm{OH}$ : Thomson Publishing.

Taleghani, M., Largani, M.S., Gilaninia, S., \& Mousavian, S.J. (2011). The role of customer complaints management in consumer satisfaction for new industrial enterprises of Iran. International Journal of Business Administration. 2(3), 14.

Tehubijuluw, Florentina K. (2016). The Effect of Complaint-Handling System to Enhance Patient Satisfaction through ServQual Dimensions. International Journal of Education and Research, 4(4). 